\title{
Flood risk perceptions and spatial multi-criteria analysis: an exploratory research for hazard mitigation
}

\author{
Ruud Raaijmakers · Jörg Krywkow $•$ Anne van der Veen
}

Received: 12 April 2007/Accepted: 25 October 2007/Published online: 11 March 2008

(C) The Author(s) 2008

\begin{abstract}
The conventional method of risk analysis (with risk as a product of probability and consequences) does not allow for a pluralistic approach that includes the various risk perceptions of stakeholders or lay people within a given social system. This article introduces a methodology that combines the virtues of three different methods: the quantifiable conventional approach to risk; the taxonomic analysis of perceived risk; and the analytical framework of a spatial multi-criteria analysis. This combination of methods is applied to the case study 'Ebro Delta' in Spain as part of the European sixth framework project 'Floodsite'. First, a typology for flood hazards is developed based on individual and/or stakeholders' judgements. Awareness, worry and preparedness are the three characteristics that typify a community to reflect various levels of ignorance, perceived security, perceived control or desired risk reduction. Applying 'worry' as the central characteristic, a trade-off is hypothesized between Worry and the benefits groups in society receive from a risky situation. Second, this trade-off is applied in Spatial Multi-Criteria Analysis (SMCA). MCA is the vehicle that often accompanies participatory processes, where governmental bodies have to decide on issues in which local stakeholders have a say. By using risk perception-scores as weights in a standard MCA procedure a new decision framework for risk assessment is developed. Finally, the case of sea-level rise in the Ebro Delta in Spain serves as an illustration of the applied methodology. Risk perception information has been collected with help of an on-site survey. Risk perception enters the multi-criteria analysis as complementary weights for the criteria risk and benefit. The results of the survey are applied to a set of scenarios representing both sea-level rise and land subsidence for a time span of 50 years. Land use alternatives have been presented to stakeholders in order to provide the regional decision maker with societal preferences
\end{abstract}

R. Raaijmakers $\cdot$ J. Krywkow $(\bowtie) \cdot$ A. van der Veen Department of Water Engineering and Management, University of Twente, P.O. Box 217, 7500 AE Enschede, The Netherlands e-mail: j.krywkow@ctw.utwente.nl

Present Address:

R. Raaijmakers

Grontmij b.v., De Holle Bilt 22, P.O. Box 203, 3730 AE De Bilt, The Netherlands 
for handling risk. Even with limited resources a characteristic 'risk profile' could be drawn that enables the decision maker to develop a suitable land use policy.

Keywords Flood risk - Risk perception - Psychometric paradigm ·

Spatial multi-criteria analysis $\cdot$ Land use $\cdot$ Sea-level rise $\cdot$ Risk-benefit tradeoff

\section{Introduction}

According to its conventional definition, risk is considered to be quantifiable. An objective measurement of risk can be produced by analysing probabilities and consequences (Helm 1996). The most widely used equation to express risk is probability multiplied by (negative) consequence, although many more definitions with other combinations of probability and consequence are available in the literature (Blaikie et al. 1994; Green 2004). However, in the Bayesian way of thinking, objectivity does not exist in the context of measuring. Furthermore, risk can be considered both as a way of expressing uncertainty, and as a collection of perceptions. This means that risk should be considered to be a judgement rather than a fact (Aven and Kristensen 2005). In this approach, 'probability' is an expression for the state of knowledge, that depends on the information and the knowledge of the individual who assigns it. Hence, no universal and true probability exists.

Risk perception is characterised as the intuitive judgement of individuals and groups of risks in the context of limited and uncertain information (Slovic 2000). Based upon the psychometric paradigm (Slovic 1987), people tend to make quantitative judgements about the current and desired level of riskiness, and the desired level of regulation for each type of hazard. Depending on the judgement of particular hazard characteristics, the psychometric paradigm allows us to compare risks associated with various hazards. Kraus and Slovic 1988) distinguish numerous risk characteristics that oppose each other on the risk perception spectrum: (1) voluntary versus involuntary risks; (2) chronic versus catastrophic risks; (3) certainly not fatal versus certainly fatal; (4) known to be exposed and not known to be exposed; (5) immediate and delayed; (6) known to science and not known to science; (7) not controllable and controllable; and (8) old and new. Many of these characteristics tend to be highly correlated to each other. For example, a risk that appears to be controllable is perceived as less threatening. In their Taxonomic Analysis of Perceived Risk, (Slovic 1984) have indicated that the entire range of characteristics can be condensed to two (or three) higher order characteristics or factors. The two factors dread risk and unknown risk can together be used as an indicator. The higher the hazard score for these two factors, the higher the perceived risk, the more people want to see the risk reduced (Kraus and Slovic 1988).

Voluntariness is a determining characteristic within the psychometric paradigm. It is defined as the freedom of choice a person has to expose him or herself to a particular risk (Starr 1969). The freedom of choice is highest if (Vlek and Stallen 1980):

- There is a large number of available alternatives with similar perceived benefits;

- An individual is not significantly influenced by a social environment in his or her choice;

- A person has significant influence on the currently selected behaviour;

- The importance of the foreseen benefits for fulfilling major individual or societal values or essential human needs is small. 
"When an individual examines a risk or determines his or her favour towards it, he or she has three options: (1) accept the level of risk, (2) reduce the risk or (3) avoid it altogether." (Sharlin 1989, p. 262). When an individual voluntarily decides to expose him or herself to a risk, the individual is assumed to have the option of avoiding this risk. Hence, there must be some motivation to take the risk. We assume that individuals weigh the perceived risk against the perceived benefit of an activity. The larger the perceived benefit of an activity the larger the accepted perceived risk (Fischhoff et al. 1978; Starr and Whipple 1980; Vlek and Stallen 1981). Not only the risks, but also the benefits of hazardous events can be perceived differently by individuals. When the individual accepts the risk, either the level of risk is acceptably small, or the perceived benefit of the activity outweighs the risk. In the latter case reducing a risk typically leads to a reduction of benefits, which poses many dilemmas for a society. In other words, in case of voluntary risks a society has to make the trade-off between risk and benefit (Fischhoff et al. 1978). That trade-off is the central element in this article.

\section{Research question}

The way a trade-off is made depends on the nature of the risk, in this case a flood. Each flood poses a hazard with different characteristics and consequences. In other words a specific hazard falls within a larger hazard domain (Kraus and Slovic 1988). For flood risk the differences among flash floods, riverine floods and storm surges must be considered. Within one hazard domain, numerous individual risks all of a different nature can be identified. Thus, depending on the context or story line, which describes the characteristic circumstances under which the risk is imposed, the perceived risk for a single event will be evaluated individually. This article examines how the notion of trade-off between perceived risk and benefits can be applied to natural hazards. See Green et al. (1991) and Chowdhury (2003) for an earlier discussion of this topic. Chowdhury (2003) mentions the fact that risks are sometimes tolerated, because they may also entail benefits for the risk taker. He investigates attitude of individuals towards a tolerable level of flood risk and willingness to accept environmental changes. In this article risk perceptions are based on risk characteristics (Slovic 2000). Furthermore, a typology of risk characteristics for flood hazards is developed. The difference between attitudes and perceptions is that attitudes are evaluations of reality, whereas perceptions relates to the process of understanding. Perceptions and communication are important elements in current risk literature (Fischhoff et al. 1997; Boholm 1998).

Besides the typology, the second innovative element in this study is the implementation of the trade-off of risk and benefits into a decision framework. One of the well-known problems in (spatial) multi-criteria analysis is the application of weights for criteria (Voogd 1983; Janssen 2001; van Herwijnen 1999). A mechanism is proposed to insert risk perceptions into a spatial multi-criteria analysis, so as to reflect societal preferences for the trade off between risks and benefits.

\section{Case study}

In order to illustrate the methodology a case study in Spain is applied where land use change is a means of dealing with relative sea-level rise. The Ebro Delta in Spain is a coastal zone which is not protected by dunes or dikes, but only by the beach itself. This 
means that during storm events the water level rises, and as a consequence the beach and the hinterland are inundated. Parts of the coastal zone are eroded, and the sediments are deposited in the hinterland or elsewhere on the coast (Jiménez 1997). Storm induced flooding and coastal erosion cause damage to land use functions in the hinterland, which at present mainly includes damage to agriculture and natural ecosystems. Farmers in the area demand protection from flooding, while ecologists see damage to ecosystems as a natural process. Civilians in a flood-prone area not protected by flood defence structures, consciously have to make a trade-off between the risk of experiencing damage due to flooding and the benefit of the use of land in a flood plain. As a result of climate-change-induced trends of sea-level rise, authorities in the delta have to make a choice between a voluntary agreement of small economic consequence with a high damage probability on the one hand, and protection by flood defence structures with a small probability of failure on the other.

This case study describes the potential of our methodology and illustrates the well known difference of risk perceptions between lay people and experts.

\section{Methodology}

For the development of the methodology extensive literature research was carried out. Social sciences engineering literature were combined to gain a new perspective of risk within a decision process. The case study consisted of two phases: first, a scenario analysis was conducted. Two types of scenarios were taken into consideration: (1) storm-induced flood scenarios, and (2) land use development scenarios. The combination of the two scenarios was input for comprehensive GIS computations on monetary damage and nonmonetary changes in environmental quality.

Second, a survey analysis was conducted. A questionnaire was prepared for local stakeholders, including questions on risk perceptions. The questions were designed according to the approach of Kraus and Slovic (1988, p. 447). The respondents were individuals, representing the following stakeholder groups: the rice farmers association, the water distribution co-operative, the salt manufacturer, the tourism industry, local and regional authorities and park managers.

\section{Outline}

In Sect. 6, characteristics of risks are described. Section 7 explores the trade-off between risk and benefit for land use decisions and the influence of risk perception on this trade-off. Section 8 presents a discussion on the relationship between floods, land use change and risk perceptions. Section 9 elaborates on the implementation of the risk benefit trade-off and risk perception in spatial multi criteria analysis. Section 10 presents the case study. Finally, Sect. 11 draws conclusion about the application or risk perception in risk assessment, and discusses the implications for future research projects.

\section{Risk characteristics}

The standard approach to studying risk perception is the development of a taxonomy for hazards in order to understand the nature of the risk, and human response towards these 
risks. An often used approach is the psychometric paradigm (Slovic 1987). Using this paradigm individuals rate judgements about risk characteristics, as described above, on an ordinal scale. Alternatively, the characterisations of voluntariness, dread, the knowledge of those exposed, and the degree of control over the flood risk are used. For natural hazards dread is often characterised as worry. Knowledge of the risk among those who are exposed is defined as awareness and control over the risk as preparedness (Slovic et al. 1984). These characteristics will be used throughout this article, and are defined in the remainder of this section.

\subsection{Awareness}

Flood risk awareness could be defined as knowledge or consciousness of the flood risk that an individual or a group of individuals is exposed to. We can roughly distinguish three levels of awareness:

1. Expert awareness: knowledge of risk assessment with the least uncertainties about probabilities and consequences of the hazard. This also applies for well informed lay people;

2. Underestimation of probability of occurrence of the hazard or consequences of the hazard (as determined by expert risk estimation);

3. The exposed are ignorant of their risk exposure.

In the last two cases the policy maker is responsible for increasing risk awareness. Flood risk awareness increases when (1) a society is confronted with a hazard; and (2) information and education about the hazard is more widely available, and this information has implications for appropriate actions (King 2000). However, a society or a community tends to forget about risks associated with infrequent events and as a result awareness may decline (Arthurton 1998). An example is the inundation of the Maas River in the Netherlands in 1925 and 1993. A time span of almost 70 years reduced awareness among affected communities. Residents along the river were not prepared for the 1993 inundation. The subsequent event with similar severity was only 2 years later in 1995 . The local population was much better prepared, since the memory of the 1993 event was still present in their minds. Provision of information to, or education of the public usually increases awareness. For example, in the European Union the improvement of environmental observation increased the availability of flood risk data for flood experts as well as for policy makers (Mitchell 2003).

\subsection{Worry}

Worry, or even fear, depends on the awareness of the frequency of occurrence of certain hazards. Depending on the expected severity of the consequences of the hazard individuals may worry more or less about socio-economic effects of flooding such as economic damage, damage to ecology or health, the disruption of family life and loss of life (Tapsell et al. 2002). The more people worry about the risk, the larger the demand from that group of individuals is to reduce the risk. In the event that solutions are known, there will be a larger willingness-to-pay to reduce the risk (Savage 1993). A risk can be reduced if individuals are prepared to deal with that risk. When preparedness increases, individuals 
and groups are more capable of controlling the negative consequences of a risk. Consequently, preparedness requires awareness and the readiness to limit losses (Kron 2002).

\subsection{Preparedness}

Preparedness (pre-flood) is both the capability of coping with a flood throughout the inundation period, and post-flood recovery capability and strategies (van der Veen and Logtmeijer 2005; Floodsite 2006). Preparedness can be described in social, technical, economic and institutional dimensions. The technical dimension refers to technical measures on an individual or group basis in order to reduce the material damage due to a flooding. These can be permanent measures, such as changing the exterior and interior design of buildings or temporal measures, such as emergency equipment and temporary reinforcement. The social dimension refers to actions taken by individuals before and during a flood event as well as coping with the consequences of the event. This depends in large part on personal skills and knowledge of dealing with inundation effects. Local authorities should have proper evacuation schemes, emergency supplies and volunteers. In the long-run restrictive work schedules of employees limit the recruitment of volunteers, for example if local employees cannot get exemption from work for emergency response situations. In order to prevent significant post flood inconvenience and social distress residents as well as businesses have to be prepared for the post flood phase, and community relationships have to be strengthened (Buckland and Rahman 1999). The institutional dimension refers to the design and communication of an action plan in case of flooding (e.g., evacuation schemes and training of emergency staff). The economic dimension refers to the reduction of the financial risk of potential victims of a flood by means of insurance. Similarly insurance with well structured premiums can stimulate the introduction of measures aimed at reduction of damages and losses (Kron 2002).

\subsection{Relationships between flood risk characteristics}

Risk perception is the relationship between the above-mentioned risk characteristics. The relationship of these flood risk characteristics to each other is shown in Fig. 1.

Awareness may lead to higher levels of worry, and as a consequence of that, higher preparedness. A better prepared society will worry less about the risk it is prepared for. Over a longer time scale $(+t)$ reduced worry may lead to a decline in awareness of the risk, as individuals tend to forget risks to which they or their communities have not been exposed to for a long period. However, it should still be noted that awareness will not necessarily lead to worry, and worry not necessarily to preparedness. Building upon the combination of awareness, preparedness and worry a typology can be designed that portrays the state of mind of individuals. Figure 2 depicts this typology in a set of radial diagrams.

Fig. 1 Relationship between flood risk characteristics

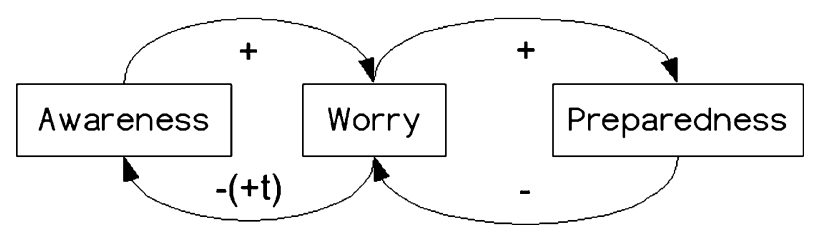




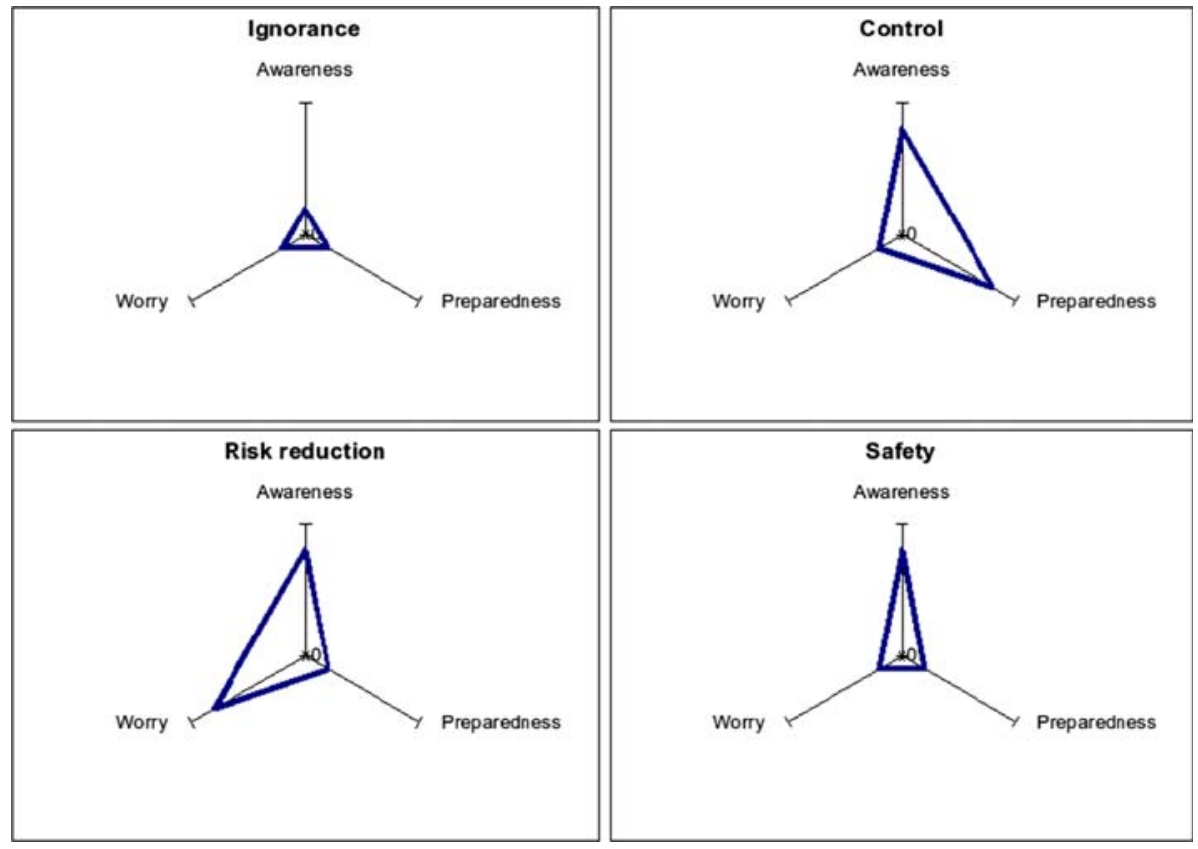

Fig. 2 Typologies of risk characteristics

The four types of risk characteristics are:

- Ignorance: An ignorant individual will not worry about, and will not be prepared for the risk because he or she is not aware of it;

- Safety: An individual who imagines him or herself to be safe, will not worry, and is thus not prepared for a risk, because the risk is acceptably small (or believed to be small) or the individual may be prepared to take risks;

- Risk reduction: An individual who is highly aware, worried and badly prepared will demand risk reduction. When an individual considers exposure to a hazard as involuntary, he or she will assume the responsibility for preparing the population for a hazard lays in the hands of authorities, instead of taking individual action;

- Control: When an individual feels prepared, then he of she has a sense of control over the risk, and is, as a consequence, less worried.

The need for risk reduction is determined by the level of worry about the risk. Worry results from the awareness of a high risk and the lack of preparedness for this risk. Worry in turn can be related to willingness-to-pay as an individual invests in risk reduction. These risk reducing measures typically result in reduced benefits of existing land use. Examples are land uses changes, building restrictions and monetary investments in safety measures.

Awareness and preparedness can be directly influenced by public policy. A policy might result in measures such as educating and informing citizens, or technical protection measures. A change in the level of worry is usually not the direct result of a given policy, but the result of changes in awareness and preparedness.

Worry is a valuable indicator in determining public preferences in the trade-off between risk and benefit. This means a high level of worry concerning a risk will lead to a greater 
societal basis for risk reducing measures. Worry is the characteristic that links risk perception to the risk-benefit trade-off. Therefore, worry is used in this article as the characteristic that determines the preference for risk reduction or retaining existing benefits.

\section{Trade-offs}

When an individual accepts a risk, two situations can be distinguished: either the level of risk is acceptably small, as a society handles risks with the maintenance of existing policies, or the (perceived) benefit of a given activity outweighs the risk, as for example is the case for extreme sports activities. The greater the perceived benefit of a particular activity, the greater the risks that an individual or a society is willing to accept. Once risk is seen as a judgement, the trade-off is one between perceived risk and perceived benefit. Since perceived risk is expressed in terms of risk characteristics, this means that on any level of benefit more and higher risk is tolerated, if people are not worried (Fischhoff et al. 1978).

In this article the concept of risk characteristics is applied to flood risk management for land use changes in flood prone areas. Damages due to flooding may be tangible as well as intangible. Benefits of land use can be seen as outputs. Two sorts of outputs are distinguished (Wiggering et al. 2006): (1) commodity outputs (tangible benefits), which are defined as the goods that are sold on a market. Non-commodity outputs (intangible benefits) (2) may be the production of positive externalities or the reduction of negative externalities. Examples of positive externalities are bird habitats and visual amenities, while an example of the reduction of negative externalities is the reduction of flood risk. How benefit is perceived depends on the assigned relative importance to each of the outputs.

As stated above (Fig. 2) worry links risk perception to the benefits of risk taking:

- If levels of worry are high, there will either be a demand for risk reduction in terms of lower probabilities of damage or a demand for reduced effects/consequences. This implies that an individual will not want to reap the positive consequences and positive benefits of the risky situation;

- If levels of worry are low, an individual will want to continue to benefit from the risky situation and take the risk: the individual believes that society is in control, feels safe or is completely ignorant of the situation. In the latter case, risk communication becomes important.

\section{Land use changes and flood risk perceptions}

For effective land use policy in flood prone areas it is useful to compare land use alternatives based upon their performance with respect to risk and benefit. When risk perception is introduced in the risk-benefit trade-off, the variety of stakeholder preferences towards risk and benefits must be incorporated. This approach is essential, since the judgement of risk can differ significantly between experts and lay people (Fischhoff et al. 1978; Renn 1998; Weber and Hsee 1998). In practice a discrepancy between technical risk assessments of experts and more intuitive public perceptions can emerge. The more threatening the perceived risk by authorities, the greater the effort towards reducing the risk. Slovic (1998, p. 76) argues “... that whoever controls the definition of 
risk, controls the solution to the problem at hand." For example, a policy maker may choose the safest or most cost-efficient solution, while lay people may accept risks by voluntary agreement. The incorporation of risk perception in risk-benefit analysis may result in a more democratic and efficient land use policy in flood prone areas. Moreover, understanding public perceptions will lead to more effective risk communication, for example, by creating awareness about a risk among the public by authorities (Slovic 1993), and may eventually lead to social learning. A mutual understanding of risk perception can be achieved by the process of social learning. The aim is not necessarily to achieve a consensus, but a mutual acceptance of individual problems, and handling the various perceptions and interests among stakeholders constructively. A transparent policy process, and general insights into the system and applied methods can enhance trust and help decision makers to find adequate solutions (Ridder et al. 2005; Pahl-Wostl 2005). In the following section perceptions, communication and decision making are combined within the framework of multi-criteria analysis.

\section{Spatial multi-criteria analysis (SMCA), land use and flood risk perceptions}

Multi-criteria analysis (MCA) is an instrument often mistrusted by decision makers, as it is seen as a technocratic instrument that can be easily manipulated (Janssen 2001). One of the reasons is that criteria stemming from various domains such as economy, ecology and administration are being compared without a common denominator. However, the strength of the technique is the ability to combine information from various scientific fields. For this reason MCA is demonstrated as a tool for providing a decision framework to policy makers in this article. Spatial multi-criteria analysis (SMCA) was first described by van Herwijnen (1999).

The weakness and most challenging problem in MCA is to create weights that are credible and justifiable (Yeh et al. 1999). Weights determine the preferences for criteria from an individual point of view, and are therefore a reflection of stakeholders' perceptions. In order to make MCA a supporting tool for a democratic decision process, these weights should be a reflection of the preferences within a given group of individuals and organisations, and may not be based upon the subjective judgement of few individuals. In other words weights should be the outcome of a public participatory process rather than the assessment of a few selected experts. The innovation of this approach is that the trade-off between risk and benefits will be translated into weights in the spatial multi-criteria analysis (SMCA). Land use alternatives could be judged on the basis of the following spatial criteria:

- Risk $\left(C_{r}\right)$, with the sub criteria tangible damage $\left(C_{r t}\right)$ and intangible damage $\left(C_{r i}\right)$ (relative values) of an event with a given return period ${ }^{1}$;

- Benefits $\left(C_{b}\right)$ of land use, with the sub criteria tangible benefit $\left(C_{b t}\right)$ and intangible benefit $\left(C_{b i}\right)$ (relative values).

This methodology differs from standard SMCA approaches in the sense that weighting based upon risk perception is included.

In Sect. 6.2, 'worry' is designated as the risk characteristic which determines the preference of a community toward a particular magnitude of risk and benefits. High levels

\footnotetext{
1 A number of climate change scenarios are available. These scenarios indicate a variability in surface water level under the assumption of changing precipitation events and storm surge.
} 
Table 1 Weights and criteria in the SMCA

\begin{tabular}{|c|c|c|c|c|c|c|}
\hline & & & \multicolumn{3}{|c|}{ Alternatives $(I)$} & \multirow[t]{2}{*}{ Weight } \\
\hline & & & 1 & $2(\ldots)$ & I & \\
\hline \multirow[t]{4}{*}{ Criteria $(J)$} & Risk $\left(C_{r}\right)$ & Tangible $\left(C_{r t}\right)$ & $v_{r t}\left(p_{r t 1}\right)$ & $v_{r t}\left(p_{r t 2}\right)$ & $v_{r t}\left(p_{r t I}\right)$ & $w_{r}$ \\
\hline & & Intangible $\left(C_{r i}\right)$ & $v_{r i}\left(p_{r i 1}\right)$ & $v_{r i}\left(p_{r i 2}\right)$ & $v\left(p_{r i I}\right)$ & \\
\hline & Benefit $\left(C_{b}\right)$ & Tangible $\left(C_{b t}\right)$ & $v_{b t}\left(p_{b t 1}\right)$ & $v_{b t}\left(p_{b t 2}\right)$ & $v_{b t}\left(p_{b t I}\right)$ & $1-w_{r}$ \\
\hline & & Intangible $\left(C_{b i}\right)$ & $v_{b i}\left(p_{b i 1}\right)$ & $v_{b i}\left(p_{b i 2}\right)$ & $v_{b i}\left(p_{b i I}\right)$ & \\
\hline Total value & & & $V_{1}$ & $V_{2}$ & $V_{I}$ & 1 \\
\hline
\end{tabular}

of worry means that low-risk exposure has a higher weighting. Low levels of worry mean development of benefits has a higher weighting. The same principle is applied to the SMCA, where risk and benefit are used as criteria for an area with distinct land use functions. Consequently, the level of worry determines the weighting in the SMCA. The scores for the characteristic 'worry', which expresses risk perception, can be obtained with the help of questionnaires.

The aggregated score for worry of a given group is scaled within the range $(0-1)$. This score represents the value of the weight $\left(w_{r}\right)$ for the criterion risk $\left(C_{r}\right)$, and the weight $\left(1-w_{r}\right)$ for the criterion benefits $\left(C_{b}\right)$.

When the spatial distribution of risk, benefits and preference towards risk reduction or conservation of benefits is known, experts are able to propose a number of land use alternatives $\left(A_{i}\right)$. For each land unit the effect score $\left(p_{j i}\right)$ of the alternative $(I)$ is determined on the basis of criterion $(J)$. After spatial aggregation (average per land use polygon) and MCA standardisation (maximum standardisation) the dimensionless effect score $v_{j}\left(p_{j i}\right)$ is determined. In this SMCA, risk perception is thus expressed as a weight $\left(w_{j}\right)$ representing the preference of individuals toward risk reduction or conservation of benefits. Using this weight, the land use alternatives are ranked by, for example, the weighted summation method (Eq. 1). The alternative which receives the highest total value $\left(V\left(P_{i}\right)\right)$ is preferred based on the specific multi-criteria method (Table 1).

$$
V\left(P_{i}\right)=\sum_{j=1}^{J} w_{j} * v_{j}\left(p_{j i}\right)
$$

The result of the SMCA can be interpreted as a preference for a particular land use policy based on current flood risk perceptions. This preference does not necessarily translate directly into a political decision. It can, however, be a strong argument within a political process. SMCA supports a desirable land use policy reflecting the pluralism within a given community. A policy maker now has the ability to compare the technical risk assessment of experts to the more intuitive assessment of lay people, and possibly discovers shortcomings in previous measurements of risk. Finally, a policy maker is able to influence public risk perception. Knowledge of spatial variations in perceptions of and consequences for land use policy will lead to more effective risk communication.

\section{The Ebro Delta}

The SMCA methodology was applied to the Ebro Delta, which is a deltaic plain $200 \mathrm{~km}$ south of the city of Barcelona in the Spanish province of Catalunya. The delta has an 
emerged area of $320 \mathrm{~km}^{2}$ and a submerged area of $1825 \mathrm{~km}^{2}$ (Jiménez et al. 1997). It has been built up by the surplus of sediment discharge of the river Ebro, and has expanded for several centuries. However, due to the erection of the Ribarroja and Mequinca dams riverine sedimentation has been brought to a standstill. About $10 \%$ of the delta lies under sea level and $45 \%$ of the Delta area has an elevation of less than $50 \mathrm{~cm}$ (Jiménez et al. 1997). Although the delta has a number of shallow dunes, the only effective flood protections are the beaches. Between 1990 and 2004 there were nine storm events that have been defined as harmful (Fig. 3). In the light of subsidence and marine erosion, the sediment balance of the delta is negative in the long-run (Raaijmakers 2006).

Both geographically and economically, the delta varies significantly from the adjacent regions. The variety of uses within each land use type, however, is limited to rice farming, a nature reserve, salt manufacturing and touristic features such as beaches and secondary housing.

Socio-economic functions of the low-lying Ebro Delta such as rice cultivation and salt manufacturing have frequently been affected by both storm induced coastal erosion and flooding in recent years. Part of the coastal zone has been designated a wildlife park of international importance. Currently the tourism sector within the coastal zone is expanding, which has led to the construction of secondary housing in this area.

Due to this intensification of coastal zone use, flood risk damage is expected to increase in the future. This problem will be amplified by a predicted relative sea-level rise (Ibànez et al. 1997), which is the sum of general sea-level rise and subsidence of the delta itself. In order to compare present storm surge impacts with those in a possible future, two types of

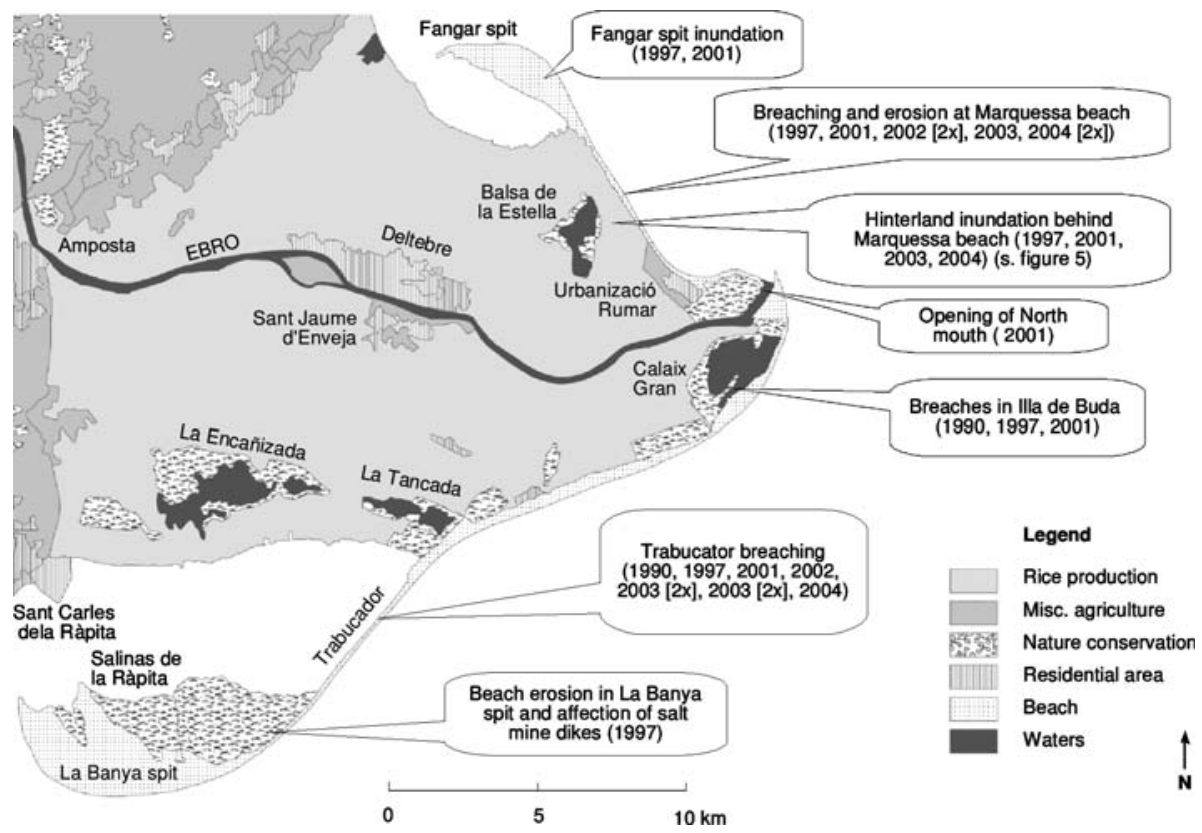

Fig. 3 Impacts of storms 1990-2004 on the Ebro Delta Coast. Sources: Jiménez and Sánchez-Arcilla 1993; Jiménez et al. 2005, 2008; European Environment Agency 2007 
scenarios were developed: storm-induced flooding scenarios combined with land use change scenarios.

Land use data, a digital elevation model (DEM) and aerial photographs were provided by the Universitat Politecnica de Catalunya. Storm surge scenarios were calculated by the University of Lund. Both universities are partners in the EU project Floodsite, part of the sixth framework programme. GIS-based overlay operations enabled the researchers to design flood maps including various land use units such as agricultural land, residential areas and conservation areas. These data have been verified with help of rectified air-borne images of previous flood events in the delta. Both the flooded surface and the estimated depth provided input for the calculation of expected values of damage.

The present land use functions and interaction between these functions were described, and land use maps based upon the CORINE biotope classification were composed. Two alternative futures for land use were developed. Data required to build the story line for the land use development scenarios, was collected from the literature and questionnaires that have been sent to the stakeholders. The first future land use alternative, the business-asusual scenario (BAU), assumes secondary housing to be developed in areas where Catalonian law does not impose building restrictions. The consequence is higher flood risk as well as higher benefits from land use. In the second alternative a land use change policy program is formulated: part of the area dedicated to rice cultivation is replaced by natural vegetation in order to reduce flood risk.

Information on risk perception was collected with the help of on-site interviews. Stakeholders have been identified according to the main land use in the Delta (rice production, tourism, nature conservation, industrial and urban area, salt manufacturing). Seven individuals representing the following groups of stakeholders have been interviewed:

- The rice producers Agrupation (RP) ${ }^{2}$, a co-operative of rice farmers in the Ebro Delta, established in 1985, this organization has about 2000 associates;

- The water distribution co-operative Communidad Regantes (WD) is responsible for the fair distribution of fresh water of the river Ebro to the rice farmers. The organization is responsible for local water policy and water planning;

- The salt manufacturer (SM) who extracts salt on the Trinidad Salt pans on the La Banya spit. This salt extraction is vital for the pink flamingo population in the wildlife park. The extracted salt is transported by lorries over the Trabucador bar, which is vulnerable to breaching during storm events;

- The restaurant at the Marquesa beach (RM). This restaurant is owned by one of the most influential land owners at Marquesa beach. The building is frequently damaged by storms directly, and due to erosion of the Marquesa beach. As of most buildings in the Ebro Delta coastal zone the restaurant is built illegally. In 2007 the owner of the restaurant has agreed to change the location of his restaurant;

- The local tourism organisation (TO) is prevailingly aimed at eco-tourists attracted by the national park and the beaches. The tourism centre of Deltebre, is the main office of tourism in the Delta.

- The town council of Sant Jaume d'Enveja (TC) one of the coastal communities. The town is one of the centers of fishery and aquaculture in the region;

- The department of coastal engineering (CE) of the regional authorities of Tarragona is responsible for coastal zone management as well for as regional land use policy;

\footnotetext{
2 The symbols for all stakeholders appear in the bar chart (Fig. 4).
} 


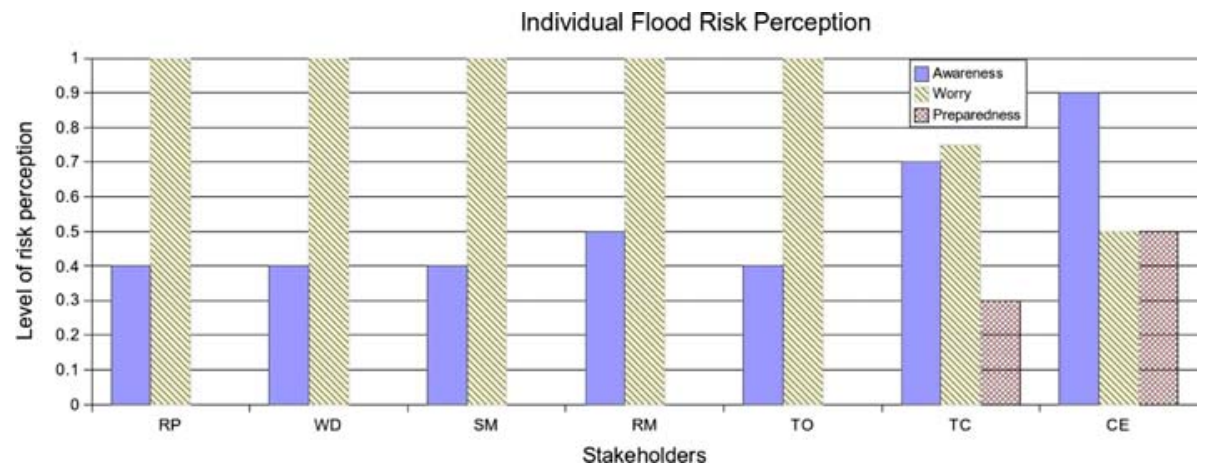

Fig. 4 Individual scores on risk perception

These stakeholders represent the main economic interests and functions of the Ebro Delta coastal zone. The management of the Ebro Delta National park was approached as well, however there was no response to the questionnaire.

The main difference between public and private stakeholders is their level of worry (Fig. 4). Private stakeholders are generally less worried than public stakeholders. From the interviews was concluded that lay people were unaware about what to do in case of a flooding. The interviewed individuals of the authorities were mostly involved in the development of land use plans. Their awareness of the risk was high. The respondents were asked to express their level of worry with respect to flooding on a scale from zero (not worried) to four ${ }^{3}$ (very worried). Moreover, they were asked to elaborate on their choice. For preparedness, a similar approach was taken. In order to find an expression for the awareness of flood risk, the respondents were questioned about their current knowledge of the 2001 flood and to judge the current hazard of flooding for the coastal zone. Answers to both questions indicated no difference in comparison to the expert awareness of flooding.

Figure 5 highlights the average score of all stakeholders on risk characteristics. This served as an input into the MCA computations. However, non-governmental stakeholders indicated a strong demand for risk reduction expressed in high levels of worry and awareness concerning the threat of flooding. This is reflected in the difference in the level of worry between the expert (CE) and the local policy maker (TC) (score 0.5 and 0.75 respectively) on the one hand, and lay people on the other (score 1).

Two future land use alternatives have been compared to the present land use situations, employing data of a recent storm event in 2001. Figure 6a depicts the current business-asusual scenario (BAU). Moreover, an estimate was made of the area to be flooded as a result of the same storm, adding an expected relative sea-level rise for 2051 (Fig. 6b).

The result of the Spatial MCA was a clear choice for the second alternative: land use change (Natural development) creates less risk. This result has implications for more effective risk communication, as it revealed a significant requirement for public preparedness. Plans to enlighten the public about appropriate response in the event of flooding were still unknown nor available to civilians living and working in the coastal zone.

\footnotetext{
3 These numbers are normalised to $0-1$ in the plot.
} 


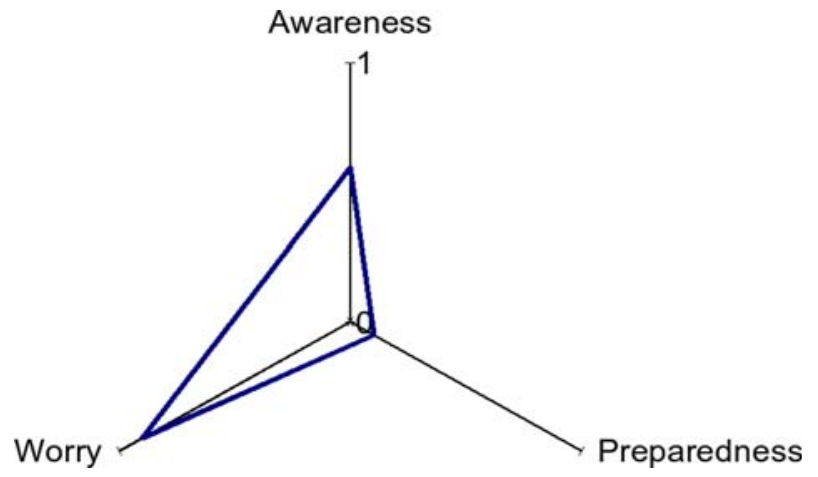

Fig. 5 Risk characteristics in the Ebro Delta
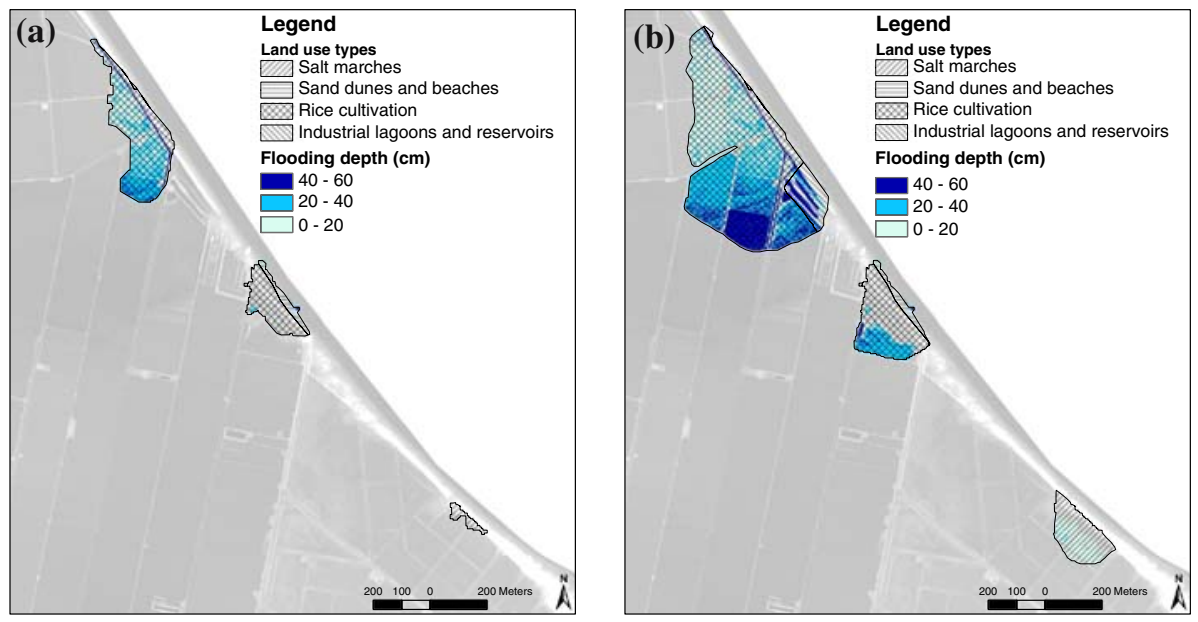

Fig. 6 Two flood scenarios. (a) Flooded area after a storm event in 2001. (b) Flooded area based on a storm scenario in 2051

\section{Conclusion}

The new approach presented in this article, strives to integrate the conventional risk methodology (technical expertise) with societal risk perception. The combination helps to explain the influence of flood risk perception on risk-benefit trade-offs. Risk perception can have diverse motivations, but since Kraus and Slovic' Taxonomic Analysis of Perceived Risk provides researchers with a clear methodology, it is possible to make this social science model operational, and apply it in an analytical framework such as a multi-criteria analysis. In this research project, flood risk perception is characterised by the notions awareness, worry and preparedness. These characteristics may be used to determine the positioning of societal preference with respect to either risk reduction or conservation of benefits. As a result, land use policy might be adjusted to meet the requirements of risk reduction within a society. Risk perception has been translated into a weight for a spatial multi-criteria analysis. This weight represents the judgement of a group of stakeholders. 
The example of the Ebro Delta demonstrates that there is a difference between the demand for risk reduction on the one hand, and living with the risk while striving for benefits on the other. In a world with increasing flood risk decision makers have to cope with that paradox if they want to implement effective land use policy in flood prone areas. In the context of risk-benefit trade-offs, the new method introduced in this article can help to reveal consequences of actions within a society, and help to make negotiation, learning and decision making processes more transparent. Although only the two criteria cost and benefits are applied a relatively complex problem is analysed. The new methodology results in a decision support framework that enables policy makers to critically reflect on the feasibility and desirability of possible policy changes.

Acknowledgements This study was possible through the European project FLOODsite (Contract Number: GOCE-CT-2004-505420). Special thanks to Vicenç Gràcia and José Jiménez for their support in Barcelona. We would like to thank Caroline van Bers for careful editing and thoughtful suggestions, and Blanca PérezLapeña for the GIS support.

Open Access This article is distributed under the terms of the Creative Commons Attribution Noncommercial License which permits any noncommercial use, distribution, and reproduction in any medium, provided the original author(s) and source are credited.

\section{References}

Arthurton R (1998) Marine-related physical natural hazards affecting coastal megacities of the Asia-Pacific region-awareness and mitigation. Ocean Coast Manage 40:65-85

Aven T, Kristensen V (2005) Perspectives on risk: review and discussion of the basis for establishing a unified and holistic approach. Reliab Eng Syst Safe 90:1-14

Blaikie P, Cannon T, Davis I, Wisner B (1994) At risk: natural hazards, people's vulnerability, and disasters, 2nd edn. Routledge, London

Boholm A (1998) Comparative studies of risk perception: a review of twenty years of research. J Risk Res $1(2): 135-163$

Buckland J, Rahman S (1999) Community-based disaster management during the 1997 Red River flood in Canada. Disasters 23:174-191

Chowdhury MR (2003) The impact of 'Greater Dhaka Flood Protection Project' (GDFPP) on local living environment-the attitude of the flood plain residents. Nat Hazards 29(3):309-324

European Environment Agency (2007) Corine land cover (CLC1990) 250 m-version 9/2007. http://dataservice.eea.europa.eu/dataservice/metadetails.asp?id=1011

Fischhoff B, Bostrom A, Quadrel MJ (1997). Oxford textbook of public health: the methods of public health, chapter risk perception and communication. Oxford University Press, Oxford, pp 897-1002

Fischhoff B, Slovic P, Lichtenstein S, Read S, Combs B (1978) How safe is safe enough? A psychometric study towards technological risks and benefits. Policy Sci 9:127-152

Floodsite (2006) Guidelines for socio-economic flood damage evaluation. T9-06-1. http://www.floodsite.net

Green C (2004) The evaluation of vulnerability to flooding. Int J Disaster Prev Manage 13(4):323-329

Green CH, Tunstall SM, Fordham MH (1991) The risks from flooding: which risks and whose perception. Disasters 15(3):227-241

Helm P (1996) Integrated risk management for natural and technological disasters. Tephra 15(1):4-13

Ibàñez C, Canicio A, Day J, Curcó A (1997) Morphologic development, relative sea level rise and sustainable management in the Ebro Delta, Spain. J Coast Conserv 3:191-202

Janssen R (2001) On the use of multi-criteria analysis in environmental impact assessment in The Netherlands. J Multi-Criteria Decis Anal 10:101-109

Jiménez J, Gracia V, Valdemoro H (2008) The response of the Ebro delta coast to the stormy period 2001-2004. Coast Eng (submitted)

Jiménez J, Sánchez-Arcilla A (1993) Medium term coastal response at the Ebro Delta, Spain. Mar Geol 114(1):105-118

Jiménez J, Sánchez-Arcilla A, Valdemoro HI (2005) Effects of storm impacts on the Ebro delta coast. Floodsite research report T26-05-01. http://www.floodsite.net 
Jiménez J, Sánchez-Arcilla A, Valdemoro H, Gracia V, Nieto F (1997) Processes reshaping the Ebro Delta. Mar Geol 144:59-79

King D (2000) You're on our own: community vulnerability and the need for awareness and education for predictable natural disasters. J Conting Crisis Manage 8:223-228

Kraus NN, Slovic P (1988) Taxonomic analysis of perceived risk: modeling individual and group perceptions within homogenous hazard domains. Risk Anal 8:435-455

Kron W (2002) Keynote lecture: flood risk $=$ flood risk $\times$ exposure $\times$ vulnerability. In: Wu B, Huang Z, Wang G, Huang G, Fang H, Huang J (eds) Flood defence 2002: proceedings of the second international conference on flood defence, Beijing. Tsinghua University, Science Press New York Ltd, pp 82-97

Mitchell J (2003) European river floods in a changing world. Risk Anal 23:567-574

Pahl-Wostl C (2005) Actor based analysis and modelling approaches. Integr Assess 5:97-118

Raaijmakers R (2006) A spatial multi-criteria analysis methodology for the development of sustainable flood risk management in the Ebro Delta. Master's thesis, University of Twente

Renn O (1998) The role of risk perception for risk management. Reliab Eng Syst Safe 59:49-62

Ridder D, Mostert A, Wolters H (eds) (2005) Learning together to manage together. Improving participation in water management. University of Osnabrück, Institute of Environmental Systems Research, Osnabrück

Savage I (1993) An empirical investigation into the effect of psychological perceptions on the Willingnessto-Pay to Reduce Risk. J Risk Uncertain 6:75-90

Sharlin H (1989) Risk perception: changing the terms of debate. J Hazard Mater 21:262-271

Slovic P (1987) Perception of risk. Science 236:280-285

Slovic P (1993) Perceived risk, trust and democracy. Risk Anal 13:675-682

Slovic P (1998) The risk game. Reliab Eng Syst Safe 59:73-77

Slovic P (2000) The perception of risk, 1st edn. Earthscan publications Ltd., London

Slovic P, Fischhoff B, Lichtenstein S (1984) Behavioral decision theory perspectives on risk and safety. Acta Psychol 56:183-203

Starr C (1969) Social benefit versus technological risk. Science 165:1232-1238

Starr C, Whipple C (1980) Risks of risk decisions. Science 208:1114-1119

Tapsell S, Penning-Rowsell E, Turnstall S, Willson T (2002) Vulnerability to flooding: health and social dimensions. Philos Trans R Soc A 360:1511-1525

van der Veen A, Logtmeijer CJJ (2005) Economic hotspots: visualising vulnerability to flooding. Nat Hazards 36(1-2):65-80

van Herwijnen M (1999) Spatial decision support for environmental management. PhD thesis, Vrije Universiteit

Vlek C, Stallen P (1980) Rational and personal aspects of risk. Acta Psychol 45:273-300

Vlek C, Stallen P (1981) Judging risks and benefits in the small and the large. Organ Behav Hum Perform 28:235-271

Voogd H (1983) Multicriteria evaluation for urban and regional planning. Pion, London

Weber E, Hsee C (1998) Cross-cultural differences in risk perception but simular attitudes toward perceived risk. Manage Sci 44:1205-1217

Wiggering H, Dalchow C, Glemniz M, Helming K, Müller K, Schultz A, Stachow U, Zander P (2006) Indicators for multifunctional land-use: linking socio-economic requirements with landscape potentials. Ecol Indic 6:238-249

Yeh C, Willis R, Deng H, Pan H (1999) Task oriented weighting in multi-criteria analysis. Eur J Oper Res 119:130-146 